Mehernoor F. Watcha MD, Manuel Ramirez-Ruiz MD, Paul F. White PhD MD FFARCAS, M. Barry Jones MD, Richard G. Lagueruela MD, Raghu P. Terkonda MD

\title{
Perioperative effects of oral ketorolac and acetaminophen in children undergoing bilateral myringotomy
}

Prophylactic administration of analgesics before surgery can decrease the intraoperative anaesthetic requirement and decrease pain during the early postoperative period. In a doubleblind, placebo-controlled study involving 90 healthy ASA physical status I or II children undergoing bilateral myringotomy, we compared the postoperative analgesic effects of oral acetaminophen and ketorolac, when administered 30 min before induction of anaesthesia. Patients were randomized to receive saline $\left(0.1 \mathrm{ml} \cdot \mathrm{kg}^{-1}\right)$, acetaminophen $\left(10 \mathrm{mg} \cdot \mathrm{kg}^{-1}\right)$ or ketorolac (1 $\mathrm{mg} \cdot \mathrm{kg}^{-1}$ ) diluted in cherry syrup to a total volume of $5 \mathrm{ml}$. Anaesthesia was induced and maintained with halothane and nitrous oxide via a face mask. Postoperative pain was assessed by a blinded observer using an objective pain scale. The three study groups were similar with respect to demographic data, duration of anaesthesia and surgery, induction behaviour, oxygen saturation, incidence of postoperative emesis and, recovery times. The ketorolac group had lower postoperative pain scores and required less frequent analgesic therapy in the early postoperative period compared with the acetaminophen and placebo groups. In contrast, there were no differences in pain scores or analgesic requirements between the acetaminophen and the placebo groups. We conclude that the preoperative administration of oral ketorolac, but not acetaminophen, provided better postoperative pain control than placebo in children undergoing bilateral myringotomy.

\section{Key words}

ANAESTHESIA: paediatrics;

ANALGESICS: acetaminophen, ketorolac;

PAIN: postoperative.

From the Division of Clinical Research, Department of Anesthesiology, Washington University School of Medicine, St. Louis, MO 63110.

Address correspondence to: Dr. M.F. Watcha, Department of Anesthesiology, Children's Hospital of St. Louis, $400 \mathrm{~S}$. Kingshighway, P.O. Box 14871, St. Louis MO 63110.

Accepted for publication 19th March, 1992.
L'administration prophylactique d'analgésiques avant la chirurgie peut diminuer les besoins anesthésiques peropératoires et la douleur durant la période postopératoire immédiate. Quatre-vingt-dix enfants avec un état physique ASA I ou II devant subir une myringotomie bilatérale participent à cette étude à double-insu avec un groupe contrôle-placebo. Sont comparés les effets analgésiques postopératoires de l'acétaminophène et du kétoralac administrés par voie orale 30 minutes avant l'induction anesthésique. Les patients reçoivent au hasard soit de la solution saline $\left(0,1 \mathrm{ml} \cdot \mathrm{kg}^{-1}\right)$, soit de l'acétaminophène $\left(10 \mathrm{mg} \cdot \mathrm{kg}^{-1}\right)$, soit du kétoralac $\left(1 \mathrm{mg} \cdot \mathrm{kg}^{-1}\right)$. Chacune des préparations est diluée dans un sirop à saveur de cerise pour faire un total de $5 \mathrm{ml}$. L'induction et l'entretien de l'anesthésie se font avec de l'halothane et du protoxyde d'azote administrés par masque. Un observateur non informé du médicament donné au patient évalue la douleur postopératoire à l'aide d'une échelle de douleur objective. Les variables démographiques, la durée de l'anesthésie et de la chirurgie, le comportement à l'induction, la saturation artérielle en oxygène, l'incidence des vomissements postopératoires et le temps d'éveil sont comparables entre les trois groupes. Les patients du groupe kétoralac ont un pointage de douleur postopératoire plus bas que ceux des groupes acétaminophène et placebo, et ils nécessitent moins souvent un supplément analgésique. D'autre part, il n'y a pas de différence entre les groupes acétaminophène et placebo pour la douleur et les besoins analgésiques postopératoires. En conclusion, le kétoralac, mais pas l'acétaminophène, administré par la bouche avant la chirurgie assure une meilleure analgésie postopératoire qu'un placebo chez les enfants subissant une myringotomie bilatérale.

Traditional approaches to postoperative pain management are based on patient-initiated requests for analgesic medication following the onset of pain. In children, this approach often fails because they fear needles and rarely ask for pain medication. ${ }^{1-3}$ Prophylactic analgesic therapy has been shown to be particularly useful for the control of postoperative pain in paediatric patients. ${ }^{1,2}$ However, the analgesic agents used should have minimal side effects 
and be administered by a nonparenteral route (e.g., oral or transmucosal) if intravenous access is not available.

Children undergoing bilateral myringotomy with placement of ventilating tubes (BMT) often exhibit painrelated behaviour and, if verbal, may complain of discomfort in the Postanaesthetic Care Unit (PACU) ${ }^{4,5}$ Therefore, we designed a double-blind, placebo-controlled study to compare the postoperative analgesic and side effects profiles of acetaminophen and ketorolac, a non-steroidal anti-inflammatory drug (NSAID), when administered orally in the preoperative period to children undergoing BMT. The oral route was chosen as it is the least threatening and most acceptable route of administration in children. In addition, this surgical procedure may be performed without intravenous access. ${ }^{6}$

\section{Methods}

We studied 90 healthy, ASA physical status I or II children, mean age $( \pm S D) 2.6 \pm 2.3$ yr who were scheduled to undergo elective BMT. Patients with bleeding or platelet disorders, those with a history of allergic reactions to acetaminophen or NSAID, children with clinically important renal, hepatic or cardiac disease, those undergoing emergency surgery or other procedures in addition to BMT, as well as those in whom the use of halothanenitrous oxide anaesthesia was contraindicated were excluded. This study was approved by the Washington University Human Studies Committee and written informed consent was obtained from the parents (or legal guardian) of the child.

Children were administered one of three oral preanaesthetic medications in a total volume of $5 \mathrm{ml}$ of cherry syrup $30 \mathrm{~min}$ before the induction of anaesthesia, according to a randomized double-blind placebo-controlled protocol. Group I received saline (placebo), Group II acetaminophen (10 $\left.\mathrm{mg} \cdot \mathrm{kg}^{-1}\right)$ and Group III ketorolac (1 $\left.\mathrm{mg} \cdot \mathrm{kg}^{-1}\right)$. No other preanaesthetic medications were administered.

Anaesthesia was induced and maintained with nitrous oxide and halothane via a face mask technique. The child's behaviour during induction was assessed using a fourpoint scale: 1 was assigned to a calm child, 2 to a crying child who could be easily consoled, 3 to a crying child who resisted the application of the face mask, and 4 to a severely agitated child. The time from the start of induction to loss of consciousness was recorded, along with the duration of the operation and anaesthesia (time from start of induction to arrival in the PACU).

Immediately on arrival in the PACU, at one and five minutes after arrival and subsequently at five-minute intervals, a blinded observer recorded the modified Aldrete's postanaesthesia recovery score. ${ }^{7}$ Haemoglobin oxygen saturation $\left(\mathrm{SpO}_{2}\right)$ values were recorded at these time
TABLE I Hannallah objective pain scale ${ }^{9,10}$

\begin{tabular}{lll}
\hline Observation & Criteria & Points \\
\hline Blood pressure & $\pm 10 \%$ of preoperative value & 0 \\
& $>20 \%$ of preoperative value & 1 \\
& $>30 \%$ of preoperative value & 2 \\
Crying & Not crying & 0 \\
& Crying, but stops with tender, loving care & 1 \\
& Crying without stopping, does not & \\
& respond to tender, loving care & 2 \\
Movement & None & 0 \\
& Restless & 1 \\
& Thrashing around & 2 \\
Agitation & Asleep or calm & 0 \\
& Mild agitation & 1 \\
& Hysterical & 2 \\
Verbalization & Asleep or states no pain & 0 \\
of pain & States there is pain but cannot localize & 1 \\
& Can localize pain & 2 \\
\hline
\end{tabular}

intervals using a Nellcor ${ }^{\circledR}$ N200 pulse oximeter (Nellcor Inc., Hayward, Calif.) In addition, the observer assessed the child's pain using an objective pain scale (OPS) as described by Hannallah et al. (Table I) ${ }^{8-10}$ The observer also recorded the times from arrival in the PACU to eye opening, oral intake, ambulation, "home readiness" and in patients of an appropriate age, time to response to verbal commands. Parents were permitted in the PACU, and the time from arrival of the child in the PACU to reunion with the family member was recorded. The behaviour of the child before and after the arrival of a family member in the PACU was assessed on a four-point scale where $1=\mathrm{calm}$, quiet; 2 = crying, but can be consoled; $3=$ crying, cannot be consoled, and $4=$ agitated and thrashing around. Patients with an OPS score of five or greater received rectal acetaminophen $15-20 \mathrm{mg} \cdot \mathrm{kg}^{-1}$. Patients were discharged home when they were awake, alert, accepted oral fluids and were felt to be comfortable (OPS $\leq 3$ ).

Demographic data in the three groups were compared by a one-way analysis of variance (ANOVA) with a Student-Newman-Keuls test for post-hoc comparison. The OPS and behaviour scores for the three groups were compared with a nonparametric Kruskal-Wallis test. Individual group comparisons of the OPS and behaviour scores were made using a Mann-Whitney U-test. In patients who received analgesic therapy in the postoperative period, only the OPS scores prior to rescue therapy were used in the statistical analysis. Behaviour scores before and after the patient first saw a family member in the postoperative period were compared using a nonparametric Wilcoxon signed rank test. Chi-square tests with Yates' correction and Fisher's exact test were 
TABLE II Demographic data, induction behaviour scores, duration of anaesthesia and surgery and oxygen saturation values on arrival in the PACU in the three treatment groups. All values are mean \pm SD unless otherwise stated

\begin{tabular}{llll}
\hline Group & Placebo & Acetaminophen & Ketorolac \\
\hline Number $(n)$ & 29 & 31 & 30 \\
Age (yr) & $2.5 \pm 2.2$ & $2.3 \pm 2.1$ & $3.0 \pm 2.5$ \\
Weight (kg) & $12.8 \pm 4.5$ & $12.2 \pm 4.5$ & $13.7 \pm 5.6$ \\
Sex (M/F) & $21 / 8$ & $20 / 11$ & $21 / 9$ \\
ASA physical status (I/II) & $24 / 5$ & $27 / 4$ & $24 / 6$ \\
Median behaviour scores at & & & \\
$\quad$ induction (range) & $2(1-4)$ & $2(1-4)$ & $2(1-4)$ \\
Duration of surgery (min) & $7.5 \pm 4.7$ & $7.2 \pm 4.9$ & $6.9 \pm 3.5$ \\
Duration of anaesthesia (min) & $14.5 \pm 5.8$ & $14.7 \pm 5.0$ & $13.3 \pm 4.1$ \\
Oxygen saturation on arrival in PACU (\%) & $96.5 \pm 1.9$ & $96.3 \pm 2.6$ & $96.7 \pm 1.8$ \\
\hline
\end{tabular}

TABLE III Recovery data in the three treatment groups. All times are mean \pm SD min from the end of surgery. Behaviour scores are median (range)

\begin{tabular}{|c|c|c|c|}
\hline Group & Placebo & Acetaminophen & Ketorolac \\
\hline Eye opening & $10 \pm 5$ & $12 \pm 6$ & $13 \pm 6$ \\
\hline Response to commands & $13 \pm 4$ & $19 \pm 6$ & $20 \pm 7$ \\
\hline First oral intake & $30 \pm 25$ & $28 \pm 16$ & $29 \pm 14$ \\
\hline Ambulation & $51 \pm 24$ & $74 \pm 40$ & $52 \pm 46$ \\
\hline Discharge home & $71 \pm 28$ & $77 \pm 66$ & $69 \pm 28$ \\
\hline \multicolumn{4}{|l|}{ Behaviour score in PACU } \\
\hline - Before meeting parent & $2(1-4)$ & $2(1-4)$ & $1(1-4)$ \\
\hline - After meeting parent & $1(1-3)^{*}$ & $1(1-3)^{*}$ & $1(1-3)^{*}$ \\
\hline Postoperative emesis (\%) & $10 \%$ & $10 \%$ & $20 \%$ \\
\hline
\end{tabular}

$* P<0.05$ compared with score before meeting parent.

used to compare the number of patients in each group who required analgesic "rescue" therapy in the PACU. When appropriate, Bonferroni corrections were used for multiple comparisons. A $P$ value of $<0.05$ was considered statistically significant.

\section{Results}

There were no differences among the three groups with respect to age, sex, weight, ASA physical status, behaviour scores at induction, time from ingestion of preanaesthetic medication to arrival in the PACU, the duration of anaesthesia and surgery, and the oxygen saturation values upon arrival in the PACU (Table II). There were also no differences among the three groups in the time-related modified Aldrete recovery scores or the times from the end of surgery to eye opening, age-appropriate response to commands, oral intake, ambulation and the achievement of discharge criteria for "home readiness" (Table III).

The OPS scores did not differ among the three groups upon arrival in the PACU. However, at 1, 5, 10, and 15 min after arrival in the PACU, the OPS pain scores were lower in the ketorolac group than in the acetaminophen and the placebo groups, irrespective of the presence or absence of the parent $(P<0.05$, Tables III and IV). When the highest pain score in the postoperative period was compared among the three groups, patients in the ketorolac group had lower scores than patients in the acetaminophen and placebo groups (Table IV). In addition, the number of patients who required "rescue" analgesic medication was lower in the ketorolac group than in the placebo group ( $30 \%$ vs $76 \%$, Fisher's exact test, $P<0.01$, Table V). In contrast, the OPS scores, as well as the requirements for "rescue" analgesics in the acetaminophen group did not differ from the placebo group ( $55 \%$ vs $76 \%$, Table V).

There was no correlation among behaviour scores during induction of anaesthesia and subsequent behavioural scores in the PACU. There were also no differences among the three groups in the time from the patient's arrival in the PACU to the time the child first saw a family member in the postoperative period. As expected, behaviour scores decreased significantly when the children first saw their parents in the PACU (Table III, $P<0.01$ ).

Although $20 \%$ of the ketorolac-treated patients experienced postoperative emesis (vs $10 \%$ of both the placebo 
TABLE IV Median (range) of OPS scores in patients who have not received analgesic "rescue" therapy, number of patients for which data are available at each time point of evaluation, and the highest OPS scores in the three study groups. All times are in min from arrival in the PACU.

\begin{tabular}{|c|c|c|c|c|c|c|}
\hline & \multicolumn{2}{|l|}{ Placebo } & \multicolumn{2}{|c|}{ Acetaminophen } & \multicolumn{2}{|l|}{ Ketorolac } \\
\hline & OPS (range) & $n$ & OPS (range) & $n$ & OPS (range) & $n$ \\
\hline OPS: on arrival & $2(0-7)$ & 29 & $1(0-7)$ & 31 & $0(0-7)$ & 30 \\
\hline $1 \mathrm{~min}$ & $3(0-8)^{*}$ & 29 & $1(0-7)^{*}$ & 31 & $0(0-6)$ & 30 \\
\hline $5 \mathrm{~min}$ & $4(0-8)^{*}$ & 29 & $2(0-7)^{*}$ & 31 & $0(0-6)$ & 28 \\
\hline $10 \mathrm{~min}$ & $4(0-9)^{*}$ & 27 & $2(0-7)^{*}$ & 31 & $0(0-9)$ & 25 \\
\hline $15 \mathrm{~min}$ & $2(0-5)^{*}$ & 19 & $1(0-5)^{*}$ & 22 & $0(0-4)$ & 22 \\
\hline $30 \mathrm{~min}$ & $1(0-5)^{*}$ & 11 & $0(0-5)$ & 17 & $0(0-5)$ & 21 \\
\hline $45 \mathrm{~min}$ & $0(0-4)$ & 9 & $0(0-4)$ & 15 & $0(0-4)$ & 21 \\
\hline $60 \mathrm{~min}$ & $0(0-4)$ & 7 & $0(0-4)$ & 14 & $0(0-4)$ & 21 \\
\hline Highest OPS score & $5(0-9)^{*}$ & & $4(0-7)^{*}$ & & $1(0-9)$ & \\
\hline
\end{tabular}

$* P<0.05$ vs ketorolac group.

TABLE $V$ The cumulative percentage of patients requiring analgesic therapy in the three treatment groups after arrival in the PACU.

\begin{tabular}{lccc}
\hline $\begin{array}{l}\text { Time after arrival } \\
\text { in PACU }\end{array}$ & Placebo & Acetaminophen & Ketorolac \\
\hline $10 \mathrm{~min}$ & $7 \%$ & $0 \%$ & $7 \%$ \\
$15 \mathrm{~min}$ & $28 \%$ & $29 \%$ & $17 \%$ \\
$20 \mathrm{~min}$ & $52 \%$ & $29 \%$ & $20 \%^{*}$ \\
$30 \mathrm{~min}$ & $62 \%$ & $45 \%$ & $27 \%^{*}$ \\
$45 \mathrm{~min}$ & $69 \%$ & $52 \%$ & $30 \%^{*}$ \\
$60 \mathrm{~min}$ & $76 \%$ & $55 \%$ & $30 \%^{*}$ \\
\hline
\end{tabular}

$* P<0.05$ vs placebo group.

group and acetaminophen groups), this difference was not statistically significant (Table III).

\section{Discussion}

This study demonstrates that preoperative oral ketorolac, $1 \mathrm{mg} \cdot \mathrm{kg}^{-1}$, is a more effective analgesic than acetaminophen (10 $\mathrm{mg} \cdot \mathrm{kg}^{-1}$ ) or placebo in children undergoing BMT. In contrast, oral acetaminophen, $10 \mathrm{mg} \cdot \mathrm{kg}^{-1}$, was not more effective than placebo. The postoperative OPS scores in the ketorolac group remained lower than the scores for both the acetaminophen and placebo groups at all assessment intervals from 1 to 15 min after the arrival in the PACU. The lower median pain scores recorded in the time interval from 15-60 min after arrival in the PACU reflect the absence of patients who received "rescue" analgesic therapy. Although OPS scores may be lower in the presence of increased sedation, the differences between the three treatment groups could not be explained by differences in sedation (since the Aldrete recovery scores did not differ among the three groups). In addition, the times to achieve other predetermined end-points (e.g., eye opening, response to commands, ambulation) did not differ among the three groups (Table III).
The differences in postoperative OPS scores did not reflect differences in preoperative agitation (i.e., children who cried excessively during induction did not have higher "pain" scores in the postoperative period). In our study, behavioural scores during induction did not predict postoperative behaviour either before or after the child first saw their parent in the postoperative period, although children were calmer in the presence of their parents. Finally, the differences in OPS scores among the three groups remained even if the parent was present with the child. These data suggest that preoperative oral ketorolac provided better analgesia than acetaminophen and placebo in this patient population.

In our study, analgesic medications were administered before the start of surgery in an attempt to attenuate the pain response to surgical trauma. It has been suggested that a prolonged hyperexcitable "wind up" state is established in the spinal cord after receiving an intraoperative barrage of painful stimuli. ${ }^{3}$ The prophylactic use of analgesics may decrease their postoperative requirements by reducing the noxious input to the central nervous system. ${ }^{3}$ Inhibition of prostaglandin synthesis by NSAIDs minimizes the activation and sensitization of peripheral nociceptors and thus reduces the pain and inflammatory response to surgical trauma. ${ }^{11-13}$ If NSAIDs interfere with the initiation of pain at the peripheral receptor, preoperative administration should provide improved analgesia compared with their administration after surgery. ${ }^{14}$

We administered our study medications orally, because this route is readily acceptable to children. In addition, intravenous access may not always be established for this procedure. ${ }^{6}$ Although pharmacokinetic data following intravenous administration of ketorolac are available for children, there are no similar data following oral administration in this population. ${ }^{15}$ However, ketorolac is rapidly absorbed following oral administration in adults, with peak 
plasma concentrations being achieved in $30-50 \mathrm{~min}$. Bioavailability is very high ( $>90 \%)$ and blood levels after oral or parenteral administration are comparable. ${ }^{11,16}$ Oral ketorolac has been shown to be superior to placebo, codeine, acetylsalicylic acid and acetaminophen with and without codeine in adults undergoing extractions of their molar teeth. ${ }^{11,17,18}$ Oral ketorolac has also been shown to be as effective as naproxen, ibuprofen, and a combination of acetylsalicylic acid, phenazone and dextropropoxyphene for postoperative pain management in adults. ${ }^{11,12,17-20}$

Although oral ketorolac has been reported to cause gastric irritability and emesis, ${ }^{11}$ no patient in our study vomited during induction of anaesthesia. The current guidelines for fasting for elective surgical patients suggest that adults may ingest oral medications with $30 \mathrm{ml}$ of water up to one hour before surgery. ${ }^{21}$ We believe it is unlikely that the administration of $5 \mathrm{ml}$ of oral medications $30 \mathrm{~min}$ before the induction of anaesthesia would be associated with an increased risk of aspiration in our patient population. There was also no evidence of increased postoperative vomiting or other side effects ( vs placebo) related to the prophylactic administration of ketorolac in our paediatric outpatient population. Although ketorolac can cause platelet dysfunction, increased perioperative bleeding has not been clinically apparent. ${ }^{11-20}$

Acetaminophen is widely used for managing mild postoperative pain in children but has a "ceiling effect" with respect to analgesia. ${ }^{1,2,22}$ It is well-absorbed orally with peak blood levels being achieved within $30 \mathrm{~min}$ in children. ${ }^{23,24}$ Although we administered our study medications $30 \mathrm{~min}$ before the induction of anaesthesia, there were no differences in the pain scores between the acetaminophen and placebo groups, while pain scores in the ketorolac group were lower than in the other two groups. Thus, the preoperatively administered acetaminophen $\left(10 \mathrm{mg} \cdot \mathrm{kg}^{-1}\right.$, po $)$ did not provide postoperative analgesia following BMT. However, larger doses of acetaminophen might prove to be more effective. This would explain the apparent pain relief associated with acetaminophen, $15-20 \mathrm{mg} \cdot \mathrm{kg}^{-1}$, per rectum.

This study can be criticized for the choice of a patient population undergoing an operation in which postoperative pain is assumed to be mild. However, our study (like a previous study ${ }^{5}$ ), demonstrated that postoperative pain after BMT does occur and can be decreased with effective analgesic medication. This study may also be criticized for the use of the Hannallah objective pain scale. Although pain assessment in children in the preverbal stage of development is difficult, the methods we used are wellaccepted and have been validated in the anaesthesia literature. ${ }^{1-2,8-10}$ The Hannallah OPS has been demonstrated to have interobserver reliability in infants and children, and also to have concurrent validity with the
Children's Hospital of Eastern Ontario Pain Scale (CHEOPS), a behavioural pain scale with documented validity and reliability. ${ }^{10}$

In summary, this study demonstrated that the preoperative administration of oral ketorolac provides better postoperative analgesia than acetaminophen or placebo in children undergoing bilateral myringotomy. Preoperative oral acetaminophen $\left(10 \mathrm{mg} \cdot \mathrm{kg}^{-1}\right)$ was no more effective than placebo in this patient population. Additional studies are necessary to determine if higher doses of acetaminophen would be effective in this patient population. Studies are also required to determine the optimal dose of oral ketorolac, and its efficacy as a prophylactic analgesic for more painful outpatient paediatric surgical procedures.

\section{Acknowledgements}

The authors thank the nurses and the physicians of Children's Hospital for their patience during the study, and gratefully acknowledge the secretarial help provided by Mia Bicknell during the preparation of the manuscript.

\section{References}

1 Berde $C B$. Pediatric postoperative pain management. Pediatr Clin North Am 1989; 36: 921-40.

2 Maunuksela E-L, Olkkola KT. Pediatric pain management. Int Anesthesiol Clin 1991; 29: 37-55.

3 Wall $P D$. The prevention of postoperative pain. Pain 1988; 33: 289-90.

4 Croteau N, Hai-Vu, Pless IB, Infante-Rivard C. Trends in medical visits and surgery for otitis media among children. Am J Dis Child 1990; 144: 535-8.

5 Orobello PW, Park RI, Wetzel RC, Belcher LJ, Naclerio RM. Phenol as an adjuvant anesthetic for tympanotomy tube insertion. Int J Pediatr Otorhinolaryngol 1991; 21 : 51-8.

6 American Academy of Pediatrics, Committee on Drugs, Section of Anesthesiology. Guidelines for the elective use of conscious sedation, deep sedation and general anesthesia in pediatric patients. Pediatrics 1986; 77: 754.

7 Aldrete JA, Kroulik DA. Post anesthesia recovery score. Anesth Analg 1970; 49: 924-34.

8 McGrath $P A$. An assessment of children's pain: a review of behavioural, physiological and direct scaling techniques. Pain 1987; 31: 147-76.

9 Hanallah RS, Broadman LM, Belman AB, Abramowitz $M D$, Epstein BS. Comparison of caudal and ilioinguinal/ iliohypogastric nerve blocks for the control of post-orchiopexy pain in pediatric ambulatory surgery. Anesthesiology 1987; 66: 832-5.

10 Norden $J$, Hannallah $R$, Getson $P$, et al. Concurrent validation of an objective pain scale for infants and children. Anesthesiology 1991; 75: A934.

11 Buckley $M M T$, Brogden $R N$. Ketorolac. A review of its 
pharmaco-dynamic and pharmaco-kinetic properties and its therapeutic potential. Drugs 1990; 39: 86-109.

12 McQuay HJ, Poppleton P, Carroll D, Summerfield RJ, Bullingham RES, Moore RA. Ketorolac and acetaminophen for orthopedic postoperative pain relief. Clin Pharmacol Ther 1986; 39: 89-93.

13 Dahl $J B$, Kehlet $H$. Non-steroidal anti-inflammatory drugs: rationale for use in severe postoperative pain. $\mathrm{Br} \mathrm{J}$ Anaesth 1991; 66: 703-12.

14 Dupuis R, Lemay H, Bushnelle MC, Duncan GH. Preoperative flurbiprofen in oral surgery: a method of choice in controlling postoperative pain. Pharmacotherapy 1988; 8: 193-200.

15 Olkkola KT, Maunuksela E-L. The pharmacokinetics of postoperative intravenous ketorolac in children. $\mathrm{Br} \mathrm{J}$ Clin Pharmacol 1991; 31: 182-4.

16 Mroszczak E, Jung D, Yee J, et al. Ketorolac tromethamine pharmacokinetics and metabolism after intravenous, intramuscular and oral administration in humans and animals. Pharmacotherapy 1990; 10: 33S-39S.

17 Forbes JA, Kehm CJ, Grodin CD, Beaver WT. Evaluation of ketorolac, ibuprofen, acetaminophen, and an acetaminophen-codeine combination in postoperative oral surgery pain. Pharmacotherapy 1990; 10: 94S-105S.

18 Forbes JA, Butterworth GA, Burchfield WH, Beaver WT. Evaluation of ketorolac, aspirin and an acetaminophencodeine combination in postoperative oral surgery pain. Pharmacotherapy 1990; 10: 77S-93S.

19 Vengen $O$, Doessland S, Lindback $E$. Comparative study of ketorolac and paracetamol-codeine in alleviating pain following gynecological surgery. J Int Med Res 1988; 16 : 433-51.

20 Sunshine A, Richman $H$, Cordone $R$, et al. Analgesic efficacy and onset of oral ketorolac in postoperative pain. Clin Pharmacol Ther 1988; 43: 159.

21 Goresky GV, Maltby JR. Editorial. Fasting guidelines for elective surgical patients. Can J Anaesth 1990; 37: 493-5.

22 Gaudreault P, Guay J, Nicol O, Dupuis C. Pharmacokinetics and clinical efficacy of intrarectal solution of acetaminophen. Can J Anaesth 1988; 35: 149-52.

23 Rumack BH. Aspirin versus acetaminophen: a comparative view. Pediatrics 1978; 62: 943-6.

24 Windofer $A$, Vogel $C$. Investigations concerning serum concentration and temperature following oral application of a new paracetamol preparation. Klin Paediatr 1976; 188: $430-4$. 